\title{
Additive Manufacturing of Dense Hexagonal Boron Nitride Objects
}

\begin{tabular}{|c|}
\hline CRADA final report for \\
CRADA number NFE-16-06299 \\
\hline Approved for public release. \\
Distribution is unlimited. \\
\hline
\end{tabular}

OAK RIDGE NATIONAL LABORATORY MANAGED BY UT-BATTELLE FOR THE US DEPARTMENT OF ENERGY
Andres Marquez

Beth L. Armstrong

Amy L. Elliott

Morgan Sharick

Edgar Lara-Curzio

May 12, 2017 


\section{DOCUMENT AVAILABILITY}

Reports produced after January 1, 1996, are generally available free via US Department of Energy (DOE) SciTech Connect.

Website http://www.osti.gov/scitech/

Reports produced before January 1, 1996, may be purchased by members of the public from the following source:

National Technical Information Service

5285 Port Royal Road

Springfield, VA 22161

Telephone 703-605-6000 (1-800-553-6847)

TDD 703-487-4639

Fax 703-605-6900

E-mail info@ntis.gov

Website http://www.ntis.gov/help/ordermethods.aspx

Reports are available to DOE employees, DOE contractors, Energy Technology Data Exchange representatives, and International Nuclear Information System representatives from the following source:

Office of Scientific and Technical Information

PO Box 62

Oak Ridge, TN 37831

Telephone 865-576-8401

Fax 865-576-5728

E-mail reports@osti.gov

Website http://www.osti.gov/contact.html

This report was prepared as an account of work sponsored by an agency of the United States Government. Neither the United States Government nor any agency thereof, nor any of their employees, makes any warranty, express or implied, or assumes any legal liability or responsibility for the accuracy, completeness, or usefulness of any information, apparatus, product, or process disclosed, or represents that its use would not infringe privately owned rights. Reference herein to any specific commercial product, process, or service by trade name, trademark, manufacturer, or otherwise, does not necessarily constitute or imply its endorsement, recommendation, or favoring by the United States Government or any agency thereof. The views and opinions of authors expressed herein do not necessarily state or reflect those of the United States Government or any agency thereof. 
ORNL/TM-2017/244

CRADA/NFE-16-06299

ORNL Materials Science \& Technology Division

ORNL Manufacturing Demonstration Facility

\title{
ADDITIVE MANUFACTURING OF DENSE HEXAGONAL BORON NITRIDE OBJECTS
}

\author{
Andres Marquez ${ }^{1}$ \\ Beth L. Armstrong ${ }^{1}$ \\ Amy M. Elliott ${ }^{1}$ \\ Morgan Sharick ${ }^{2}$ \\ Edgar Lara-Curzio ${ }^{1}$
}

1. Oak Ridge National Laboratory

2. Arconic Inc. (Formerly Alcoa Inc.)

Date Published: May 12, 2017

\author{
Prepared by \\ OAK RIDGE NATIONAL LABORATORY \\ Oak Ridge, Tennessee 37831-6283 \\ managed by \\ UT-BATTELLE, LLC \\ for the \\ US DEPARTMENT OF ENERGY \\ under contract DE-AC05-00OR22725
}






\section{CONTENTS}

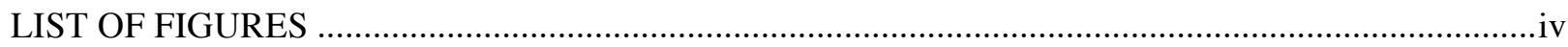

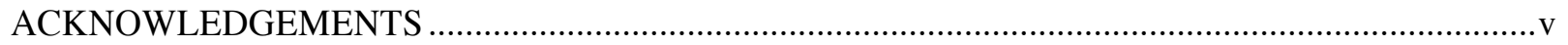

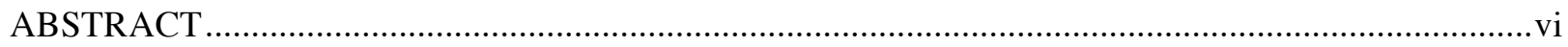

1. ADDITIVE MANUFACTURING OF DENSE HEXAGONAL BORON NITRIDE OBJECTS

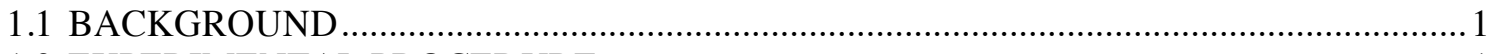

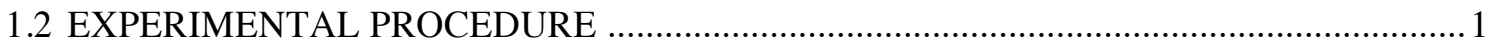

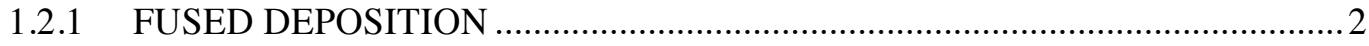

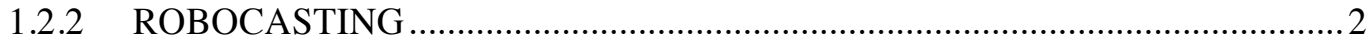

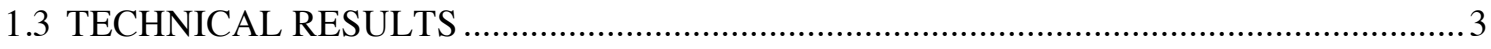

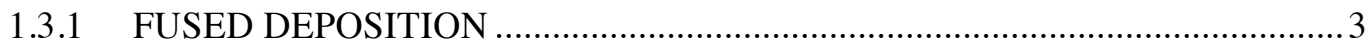

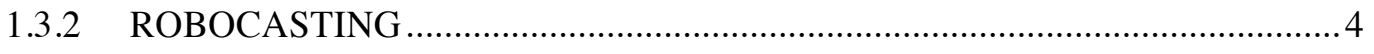

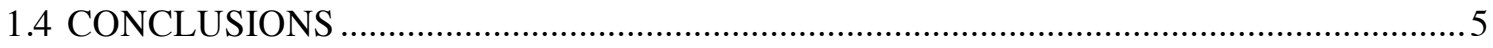

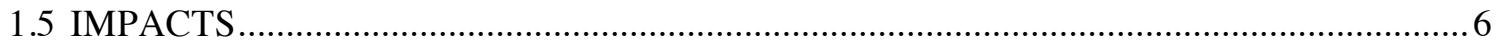

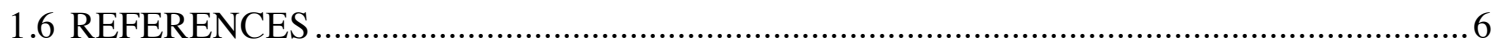

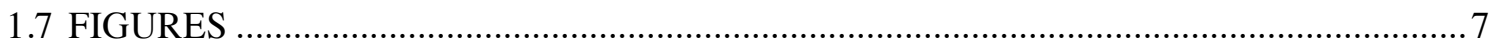





\section{LIST OF FIGURES}

Fig. 1. Illustration of idealized composite particle with diameter greater than $20 \mu \mathrm{m}$. The composite particle is comprised of boron nitride powder embedded in the same binder that would be used for binder jetting. While this approach would yield particles with good flowability for binder jetting, it would dilute the concentration of solids, which would be detrimental for sinterability and densification.

Fig. 2. Illustration of crucible geometry to demonstrate the feasibility of fabricating boron nitride objects using additive manufacturing techniques....

Fig. 3. Picture showing several segments of extruded filaments containing a $60 \%$ volume concentration of boron nitride particles. These filaments were stiff and had to be fed by hand into the printer's nozzle.

Fig. 4. Picture of extruded filaments with a $33.7 \%$ volume concentration of boron nitride particles, illustrating their flexibility.

Fig. 5. Spectrum from the longitudinal cross-sectional surface of extruded filament identifying the elements present.

Fig. 6. Chemical distribution in extruded filament. (a) optical image of longitudinal cross section of the filament. (b) distribution of boron, carbon, and nitrogen in analysis area. The light magenta color results from the overlay of red, green and blue, indicating the presence of boron nitride and carbon from the thermoplastic binder.

Fig. 7. Picture of two disks and one crucible 3D-printed using an extruded filament containing 50\% volume concentration of boron nitride particles. The diameter of the disks is $38 \mathrm{~mm}$.

Fig. 9. Zeta potential as a function of $\mathrm{pH}$ for dilute solution of boron nitride powders. The symbols and error bars reflect the average and one standard deviation about the mean, respectively, of ten individual measurements. The solid line is merely a guide to the eye.

Fig. 10. Apparent viscosity as a function of shear stress for boron nitride suspensions of varying solids loading and solvent composition. The solid lines merely guide the eye.

Fig. 11. Magnified view of the apparent viscosity as a function of shear stress for boron nitride suspensions of varying solids loading and solvent composition. Solid lines merely guide the eye.

Fig. 12. Droplet containing a 26 vol\% concentration of boron nitride with 2 wt $\%$ cationic dispersant polyethylene imine in deionized water suspension. 



\section{ACKNOWLEDGEMENTS}

This CRADA NFE-16-06299 was conducted as a Technical Collaboration project within the Oak Ridge National Laboratory (ORNL) Manufacturing Demonstration Facility (MDF) sponsored by the US Department of Energy Advanced Manufacturing Office (CPS Agreement Number 24761). Opportunities for MDF technical collaborations are listed in the announcement "Manufacturing Demonstration Facility Technology Collaborations for US Manufacturers in Advanced Manufacturing and Materials Technologies" posted at http://web.ornl.gov/sci/manufacturing/docs/FBO-ORNL-MDF-2013-2.pdf.

The goal of technical collaborations is to engage industry partners to participate in short-term, collaborative projects within the Manufacturing Demonstration Facility (MDF) to assess applicability and of new energy efficient manufacturing technologies. Research sponsored by the U.S. Department of Energy, Office of Energy Efficiency and Renewable Energy, Advanced Manufacturing Office, under contract DE-AC05-00OR22725 with UT-Battelle, LLC.

The contributions from James McMillen and Judodine Nichols of Arconic and Ryan K. Duncan, Michael Adam Smith, Kelsey L. Hedrick, Makayla S. Edwards, James O. Kiggans Jr., Harry M. Meyer III, Randy Parten, Kevin Cooley, Ercan Cakmak, Thomas R. Watkins, Hsin Wang, Shirley B. Waters, Michael P. Trammell, Darren J. Skitt, Rick R. Lowden, James W. Klett, Tom Geer, Ann Strange, and Christine Goudy from ORNL's Materials Science \& Technology Division are greatly appreciated. 



\begin{abstract}
The feasibility of manufacturing hexagonal boron nitride objects via additive manufacturing techniques was investigated. It was demonstrated that it is possible to hot-extrude thermoplastic filaments containing uniformly distributed boron nitride particles with a volume concentration as high as $60 \%$ and that these thermoplastic filaments can be used as feedstock for 3D-printing objects using a fused deposition system. Objects 3D-printed by fused deposition were subsequently sintered at high temperature to obtain dense ceramic products.

In a parallel study the behavior of hexagonal boron nitride in aqueous solutions was investigated. It was shown that the addition of a cationic dispersant to an azeotrope enabled the formulation of slurries with a volume concentration of boron nitride as high as $33 \%$. Although these slurries exhibited complex rheological behavior, the results from this study are encouraging and provide a pathway for manufacturing hexagonal boron nitride objects via robocasting.
\end{abstract}





\section{ADDITIVE MANUFACTURING OF DENSE HEXAGONAL BORON NITRIDE OBJECTS}

This phase I technical collaboration project (MDF-TC-2016-098) between Arconic Inc. and the Oak Ridge National Laboratory (ORNL) began on August 17, 2016 and was completed on January 31, 2017. Arconic is a company created by Alcoa Inc.'s separation into two independent, publicly traded companies in the second half of 2016. Alcoa Inc. spun off its bauxite, alumina, and aluminum operations to a new company called Alcoa Corp. Alcoa Inc. was renamed to Arconic Inc. and retained the operations in aluminum rolling, aluminum plate, precision castings, and aerospace and industrial fasteners. It focuses on turning aluminum and other lightweight metals into engineered products such as turbine blades for sectors including aerospace and automotive.

\subsection{BACKGROUND}

Hexagonal boron nitride is an attractive material for diverse applications because it has low density, very high melting temperature, chemical inertness, resistance to thermal shock, very low coefficient of friction, and very high thermal conductivity despite being an electrical insulator [1-2]. As molten glass, molten salts or reactive molten metals do not wet hexagonal boron nitride, it is widely used for manufacturing hardware for metal production. However, hexagonal boron nitride sinters poorly [1] and therefore, dense bodies of this material are currently limited to objects with simple geometry produced by hot pressing.

The objective of this Cooperative Research and Development Agreement (CRADA) between Arconic and UT-Battelle, LLC was to determine the feasibility of manufacturing dense objects of hexagonal boron nitride via additive manufacturing methods. The successful completion of this project could lead to new techniques for manufacturing boron nitride and other ceramic objects with complex shapes, including shapes that cannot be achieved using current manufacturing methods.

\subsection{EXPERIMENTAL PROCEDURE}

The initial research plan for this project was designed based on using binder jetting to achieve the project objectives. Binder jetting is an additive manufacturing technique in which organic binder droplets are used to selectively bond powder materials into 3D green bodies, which are subsequently sintered or infiltrated with a secondary phase [3-4]. However, preliminary experiments showed that the boron nitride powder used in this investigation didn't exhibit good flowability. It has been reported that optimum powder flowability for binder jetting is achieved with round particles greater than $20 \mu \mathrm{m}$ in diameter [5]. Although smaller particles of irregular shape are preferred for increasing the packing ratio and sinterability. To improve the flowability of boron nitride powders, the feasibility of manufacturing spherical composite particles greater than $20 \mu \mathrm{m}$ in diameter consisting of the original boron nitride powder embedded in a resin compatible with that used for binder jetting, (Fig. 1) was considered. Among the techniques that could be used for manufacturing such spheres, spray drying was identified as having a high probability of success. However, this approach was not pursued because it would result in a diluted concentration of solids, which is contrary to the goal of maximizing solids loading in order to optimize sinterability and minimize final porosity. 
Instead, two alternative approaches were pursued for manufacturing dense boron nitride objects by additive manufacturing: fused deposition and robocasting. Objects 3D-printed with these methods would be subsequently sintered.

\subsubsection{Fused deposition}

An important consideration for manufacturing objects by fused deposition is the availability of feedstock in the form of a continuous filament of uniform diameter. In this study efforts were focused on extruding thermoplastic filaments with the highest possible volume concentration of boron nitride particles. The densest possible packing in three dimensions for spheres of equal size is the close-packed hexagonal structure, which has a volume fraction of 74\% [6]. Considering the size distribution and morphology of the boron nitride particles used in this investigation, experiments were designed with the objective of manufacturing filaments with different thermoplastic binders and volume concentration of solids at different levels between $30 \%$ and $70 \%$. The selection of the thermoplastic binder was guided by the goal of producing filaments with high mechanical strength but with high flexibility to be bent and fed through the dispensing nozzle of the fused deposition system. Thermoplastic binders used in this investigation included PLA (Polylactic Acid), ABS (Acrylonitrile Butadiene Styrene), different grades of Nylon, and PCTPE (Plasticized Copolyamide thermoplastic elastomer).

The process for extruding filaments for fused deposition involved mixing boron nitride particles and melted pellets of the thermoplastic binder using a dual, asymmetric centrifugal mixer at a temperature above the melting temperature of the binder. The effects of mixing time and mixer settings on the homogeneity of the mixture were investigated and the processing parameters that yielded filaments with the most homogeneous distribution of boron nitride particles were identified. Then, the mixture was hotextruded to obtain continuous filaments of different diameters between $1.75 \mathrm{~mm}$ and $3.0 \mathrm{~mm}$ and several meters in length.

Disks of different diameter and thickness were 3D-printed using the hot-extruded filaments and a fuseddeposition system. The nozzle temperature, nozzle diameter, filament feed rate, layer height, bed temperature, and printing pattern were adjusted to achieve a continuous deposition process. The objective of fabricating disks was to identify the optimum 3D-printing parameters to subsequently 3D-print crucibles according to the schematic shown in Fig. 2, which would demonstrate the feasibility of fabricating boron nitride objects via additive manufacturing methods.

The disks and crucibles were sintered at temperatures between $1700^{\circ} \mathrm{C}$ and $1900^{\circ} \mathrm{C}$ for periods of time between 10 and 60 minutes, after a de-binding step at $400^{\circ} \mathrm{C}$. The microstructure and mechanical properties of the sintered objects were characterized using Vickers hardness and scanning electron microscopy.

\subsubsection{Robocasting}

The second processing route was focused on formulating slurries that could be dispensed according to robocasting. Robocasting is a forming process that was developed in the late 1990s to fabricate "freeform" silicon nitride components utilizing fine-sized powders [7]. Unlike fused deposition, robocasting slurries are typically binderless. The formulation of slurries also opens the possibility of producing objects by gelcasting, a technology originally developed at ORNL that has been successfully used to fabricate components with complex shape and geometry, such as turbine wheels.

The lack of hydroxyl groups on the surface of the starting powder is used to achieve the appropriate pseudo-plastic rheological behavior needed to flow to form complicated geometries. At the same time, it has the property of transitioning into a dilatant solid-state quickly. However, the lack of hydroxyl groups 
inhibits dispersion and achieving high solids loadings in suspension. Therefore, organic additives, such as polyelectrolytes and surfactants, are used to enhance dispersion of the powders to achieve higher solids loadings while maintaining or refining rheological behavior. Identification and optimization of the slurry formulation is critical to the success of a robocasting effort. Characterizing the zeta potential and the rheological behavior can aid in the selection of the appropriate surface additive for stabilization as well as the pseudo-plastic/dilatant transition.

Zeta potential measurements of the as-received boron nitride powders were carried out in dilute aqueous suspensions using electrophoretic phase analysis light scattering. Dilute suspensions with solids volume fraction of $\sim 10^{-5}$ were prepared by combining the appropriate amount of boron nitride powders and deionized water with $0.01 \mathrm{M} \mathrm{KNO}_{3}$ as the background electrolyte. The suspension $\mathrm{pH}$ was adjusted over a range of 2-10 using solutions of $1 M \mathrm{HNO}_{3}$ and $1 M \mathrm{NH}_{4} \mathrm{OH}$. The resulting suspensions were stirred to break up soft agglomerates and aged 24 hours to achieve equilibrium. The $\mathrm{pH}$ was measured prior to measurement of zeta potential values, which were calculated using Smoluchowski's equation.

Rheological measurements were carried out using a controlled stress rheometer fitted with concentric cylinder geometry. Concentrated suspensions were formulated by mixing the boron nitride powder into aqueous and mixed aqueous/organic solutions with varying dispersant concentrations. The suspensions were slow rolled on a ball mill up to 24 hours to break up soft agglomerates and allow for the boron nitride powder surfaces to fully wet and achieve equilibrium. Stress viscometer measurements were carried out by logarithmically ramping an applied shear stress from 0.15 to $1000 \mathrm{~Pa}$ at a constant frequency of $1 \mathrm{~Hz}$. All measurements were conducted at room temperature.

\subsection{TECHNICAL RESULTS}

\subsubsection{Fused Deposition}

Filaments of uniform diameter with volume concentrations of boron nitride as high as $60 \%$ were successfully hot-extruded, although these filaments were stiff and could not be bent without breaking. Therefore, they had to be fed manually into the fused deposition system. Figure 3 shows a picture of several segments of extruded filaments with a $60 \%$ volume concentration of boron nitride particles illustrating their stiffness. As expected, the flexibility of filaments increased by decreasing the concentration of boron nitride particles. For example, Fig. 4 shows filaments with a $33.7 \%$ volume concentration of boron nitride particles, illustrating their flexibility.

X-ray photoelectron spectroscopy (XPS) was used to characterize the degree of homogeneity in the composition of extruded filaments. XPS was selected because of its ability to detect light elements (e.g., boron, carbon and nitrogen) with high precision. Samples for XPS analysis were prepared using standard metallographic procedures, which involved embedding filaments in epoxy in directions parallel and perpendicular to the main axis of the filaments, followed by polishing using standard metallographic techniques. Figure 5 shows a survey spectrum of the sample revealing the chemical elements present in a filament containing 50\% volume concentration of boron nitride. In this case, the elements detected are carbon, boron, oxygen and nitrogen. Chemical compositional maps were obtained after Ar-ion sputtering by collecting the $\mathrm{C} 1 \mathrm{~s}, \mathrm{~B} 1 \mathrm{~s}, \mathrm{~N}$ 1s, and $\mathrm{O} 1 \mathrm{~s}$ signals. Figure 6 is a color-combined image of carbon (green) boron (red) and nitrogen (blue). The light magenta color in Fig. $6 \mathrm{~b}$ results from the superposition of red, blue and green, corresponding to boron nitride and carbon from the thermoplastic binder. The results from these analyses demonstrate that the spatial distribution of boron nitride particles was very uniform throughout the extruded filaments.

The role of various fused deposition parameters, such as displacement speed of the nozzle and printing strategy, on the structure of 3D-printed objects was investigated. As previously discussed, the purpose of 
printing disks was to optimize fused deposition and sintering parameters for the subsequent fabrication of crucibles. Figure 7 shows a picture of two 38-mm diameter disks of different thickness that were 3Dprinted using a hot-extruded filament with a $50 \%$ volume concentration of boron nitride particles. The printing pattern, as well as the laminated structure of the objects, are evident in the picture. Also, shown in the picture is a crucible with an outer diameter of $26 \mathrm{~mm}$.

The thermal conductivity of 3D-printed disks was measured at ambient conditions using the hot-disk test method to assess the potential of using thermoplastics reinforced with boron nitride particles in thermal management applications because plastic heat exchangers could provide lower-cost, lower-weight and higher-corrosion resistance alternatives to metallic heat exchangers. Values of the thermal conductivity of these disks in the thickness direction varied between $1.4 \mathrm{~W} / \mathrm{m} \mathrm{K}$ and $1.7 \mathrm{~W} / \mathrm{m} \mathrm{K}$. These results are encouraging because, although these structures were not optimized for this application, these values of thermal conductivity are of the same order of magnitude of those of epoxy reinforced with $50 \%$ volume concentration of magnesium oxide particles, which is widely used for thermal management applications in power electronic modules. Values for these materials have been reported between $2.0 \mathrm{~W} / \mathrm{m} \mathrm{K}$ and 3.0 $\mathrm{W} / \mathrm{m} \mathrm{K}[8]$.

3D-printed objects were sintered in argon at temperatures between $1700^{\circ} \mathrm{C}$ and $1900^{\circ} \mathrm{C}$ for periods of time between 10 minutes and 60 minutes, after a de-binding step at $400^{\circ} \mathrm{C}$. Sheets of Grafoil ${ }^{\circledR}$ were used to prevent interaction between the printed samples and the graphite fixtures of the sintering furnace. Figure 8 shows the cross-section of a disk with a $50 \%$ volume concentration of boron nitride sintered at $1900^{\circ} \mathrm{C}$. It was found that sintered objects were dense and had a uniform microstructure as illustrated in Figure 8, and as expected, the degree of densification increased with increasing sintering temperature. Vickers hardness was measured on polished surfaces parallel and perpendicular to the axis of the disks with an applied load of 100 grams and a duration of 10 seconds. The average value on the surface perpendicular to the axis of the disks was $0.14 \pm 0.01 \mathrm{GPa}$, while that of the surface parallel to the axis was $0.17 \pm 0.01 \mathrm{GPa}$. These Vickers hardness values are comparable to values reported for dense sintered boron nitride, which are in the range between 0.15 and $0.24 \mathrm{GPa}$ [9] and demonstrate the high degree of densification achieved. At the time of writing this report, sintering of crucibles had not been completed.

\subsubsection{Robocasting}

Zeta potential measurements were carried out on boron nitride suspensions, and the results are shown in Fig. 9. The zeta potential is a measure of the repulsive forces between adjacent particles of similar charge, and it is an indication of stability. If particles have high potential $(>30 \mathrm{mV}$, preferred $>60 \mathrm{mV})$ and/or if they are small, repulsive forces will be high, which minimizes flocculation. When zeta potentials are in the range $\pm(10-30) \mathrm{mV}$, attractive forces are larger than repulsive forces, resulting in particle agglomeration and slurry instability. Moreover, rapid flocculation will occur in the range of $\pm(0$ 5) $\mathrm{mV}$.

The isoelectric point (IEP) is the $\mathrm{pH}$ value where there is negligible or zero charge. When formulating a suspension, the IEP point identifies either the $\mathrm{pH}$ range that should be avoided during processing to prevent powder agglomeration and slurry instability and/or the candidate dispersant for steric stabilization of the powder. When the IEP is less than $\mathrm{pH} 6$, a cationic dispersant is typically selected to start formulating studies. At low pHs, a cationic dispersant is more protonated than at higher pHs. Typically, the degree of protonation is proportional to the extension of the polymer chain. The more extended the chain length, the greater the particle separation distance, thus realizing the fuller potential benefit of the dispersant and steric forces. Given the value of IEP at 3.7 (Fig. 9), the cationic dispersant polyethylene imine (PEI) was selected as the starting additive to control dispersion of boron nitride powder. 
A solids loading study was conducted with PEI to determine maximum solids loadings achievable as well as to understand wetting behavior of boron nitride in aqueous solutions. Solids were incrementally added to a solution of premixed water and dispersant at $2 \%$ concentration by weight of solids and ball milled to break up agglomerates and assist in wetting the boron nitride powder. The wetting of the powder was dependent upon solids loadings and time in solution. The lower the solids loadings, the more easily the powder dispersed. At approximately 15 vol\% solids, wetting drastically slowed, but improved with time. It was assumed that this was due to the increase of hydroxyl groups forming on the surface of the boron nitride. Solids loadings were increased by adding powder incrementally over time (added 1-5 vol\% solids/4-12 hours), and 26 vol\% was ultimately achieved before the slurry stopped flowing.

One way to improve wetting behavior when powders exhibit some hydrophobicity consists in substituting a solution azeotrope, e.g., ethanol/water or isopropanol/water mixtures. Suspensions of varying solids content and solvent compositions were prepared, and the characteristics of these suspensions are listed in Table 1. Utilizing an azeotrope allowed for a significant increase in solids loadings from 26 to $\sim 33$ vol\% boron nitride.

Table 1. Summary of boron nitride batch compositions used to evaluate the effect of azeotropes on boron nitride wetting behavior

\begin{tabular}{|l|l|l|c|}
\hline ID \# & vol \% solids & SOLVENT & \% solvent \\
\hline BN110316-1 & 26 & Deionized water (DI) & 100 \\
\hline BN110316-2 & 26 & DI/Ethanol & $40 / 60$ \\
\hline BN110316-3 & 26 & DI/Isopropanol & $95 / 5$ \\
\hline BN110316-3B & 32.9 & DI/Isopropanol & $95 / 5$ \\
\hline BN110316-4 & 28.8 & DI/Isopropanol & $95 / 5$ \\
\hline
\end{tabular}

However, the increase in solids loading also had an impact on the rheological behavior of boron nitride suspensions as seen in Figures 10 and 11. Figure 10 shows the apparent viscosity as a function of applied shear stress for four of the five batches fabricated. BN110316-3B was too viscous to load the concentric cylinders and as a result was not characterized. The apparent viscosity curves for the batches formulated with only deionized water or deionized water/isopropanol mixtures were plotted separately to assess the variability in the data. Although the exact nature of this variability is not known, it is believed that this is attributed to inconsistent wetting of the boron nitride powder surface, and indicates that this azeotrope in this concentration is not effective. Even though the solids loading and the rheological behavior are not optimized, the structure of a boron nitride droplet can be maintained as can be seen in Fig. 12, which is a promising result highlighting the feasibility of this approach, which requires a level of rigidity of the suspension upon application.

\subsection{CONCLUSIONS}

The feasibility of manufacturing hexagonal boron nitride objects via additive manufacturing techniques was investigated. The optimum processing conditions for hot-extruding thermoplastic filaments containing boron nitride particles were identified, and it was shown that it is possible to hot-extrude filaments containing boron nitride particles with a volume concentration as high as $60 \%$.

Objects 3D-printed by fused deposition were sintered at elevated temperatures and exhibited high degree of densification, as demonstrated by their Vickers hardness. Although a slight axial compressive load was applied during sintering, it should be possible to manufacture boron nitride objects by pressureless sintering by adding sintering aids to the filaments.

The rheological behavior of hexagonal boron nitride in aqueous solutions was investigated and it was found that the addition of a cationic dispersant to an azeotrope yielded slurries with a volume 
concentration of boron nitride as high as 33\%. Although these slurries exhibited complex rheological behavior, the results from this investigation provide guidelines for further increasing solids loading and for tailoring their behavior to enable the manufacture of hexagonal boron nitride objects via robocasting.

An approach for improving the flowability of boron nitride powders was identified, which could enable the use of binder jetting for 3D-printing boron nitride objects.

\subsection{IMPACTS}

Ceramic materials are often the only materials choice for applications at elevated temperature or under extreme environmental or tribological conditions. Fabricating ceramic objects with complex shapes requires expensive machining and in many cases these are not possible to attain with existing manufacturing techniques. Additive manufacturing enables the possibility of manufactuiring ceramic components with complex arbitrary shapes, that could improve many industrial processes and creating new ones.

\subsection{REFERENCES}

1. J. Greim and K. A. Schwetz, (2006) "Boron Carbide, Boron Nitride, and Metal Borides," Ullmann's Encyclopedia of Industrial Chemistry

2. A. Lipp, K. A. Schwetz, and K. Hunold. (1989). "Hexagonal boron nitride: Fabrication, properties and applications." Journal of the European Ceramic Society, 5(1), 3-9.

3. E. M. Sachs, J. S. Haggerty, M. J. Cima, P. A. Williams, "Three-dimensional printing techniques,” U. S. Patent No. 5,204,055, April 20, 1993

4. I. Gibson, D. W. Rosen, and B. Stucker, Additive Manufacturing Technologies. Boston, MA: Springer US, 2010.

5. B. Utela, D. Storti, R. Anderson and M. Ganter, "A review of process development steps for new material systems in three-dimensional printing (3DP)," Journal of Manufacturing Processes 10 (2008) 96-104

6. H. M. Jaeger and S. R. Nagelb, "Physics of the Granular State," Science, Vol. 255, No. 5051 (Mar. 20, 1992), pp. 1523-1531

7. J. Cesarano, III, “A Review of Robocasting Technology," Mat. Res. Soc. Symp. Proc., Vol 542, pp 133-13, 1999.

8. A. A. Wereszczak, T. G. Morrisey, C. N. Volante, P. J. Farris, R. J. J. Groele, R. H. Wiles and H. Wang, "Thermally Conductive MgO-Filled Epoxy Molding Compounds," IEEE Transactions on Components, Packaging and Manufacturing Technology, Vol. 3, No. 12, December 2013

9. B. Ertug (2013). Powder Preparation, Properties and Industrial Applications of Hexagonal Boron Nitride, Sintering Applications, Dr. Burcu Ertug (Ed.), InTech, DOI: 10.5772/53325. 


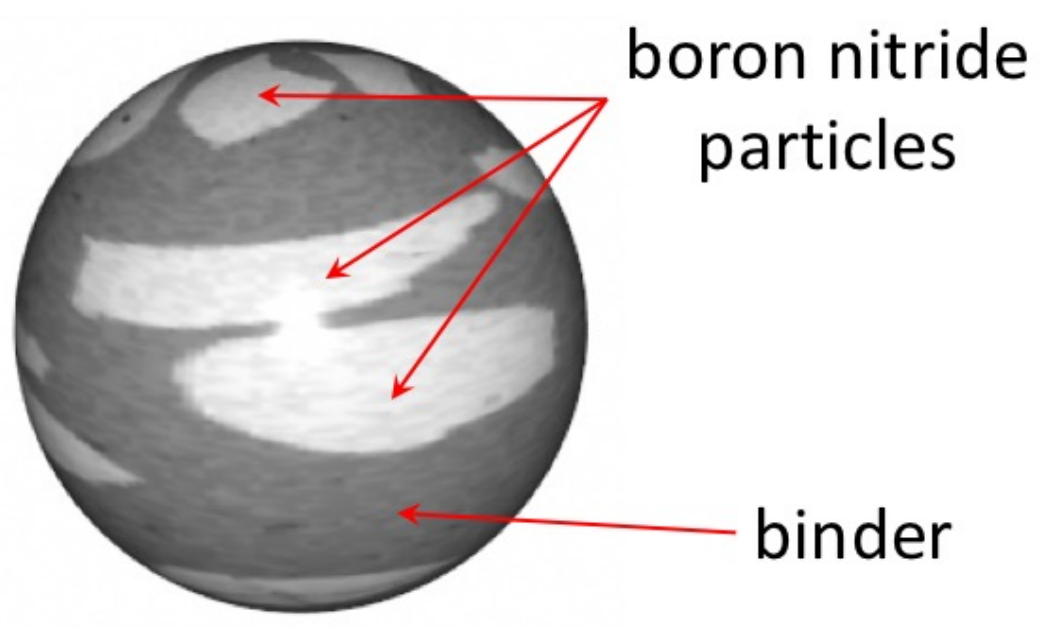

Fig. 1. Illustration of idealized composite particle with diameter greater than $20 \mu \mathrm{m}$. The composite particle is comprised of boron nitride powder embedded in the same binder that would be used for binder jetting. While this approach would yield particles with good flowability for binder jetting, it would dilute the concentration of solids, which would be detrimental for sinterability and densification. 


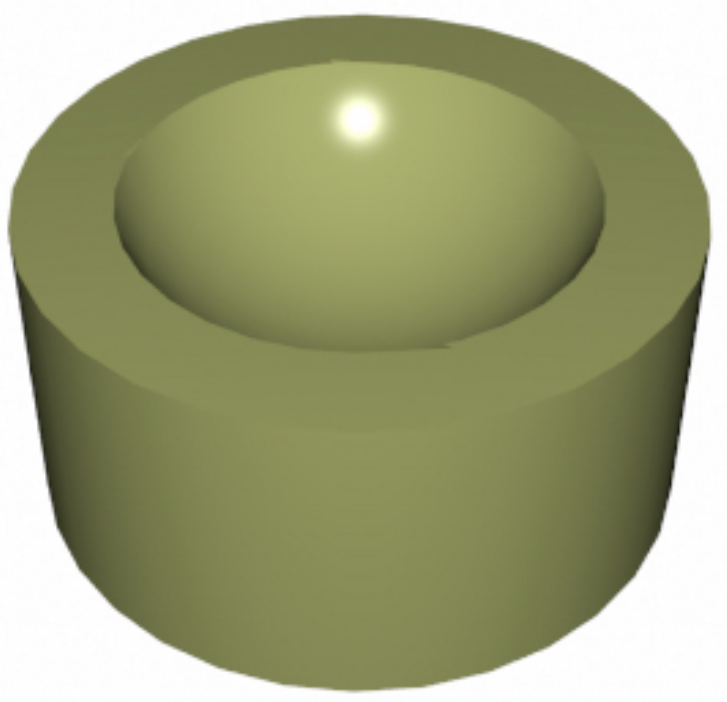

Fig. 2. Illustration of crucible geometry to demonstrate the feasibility of fabricating boron nitride objects using additive manufacturing techniques. 


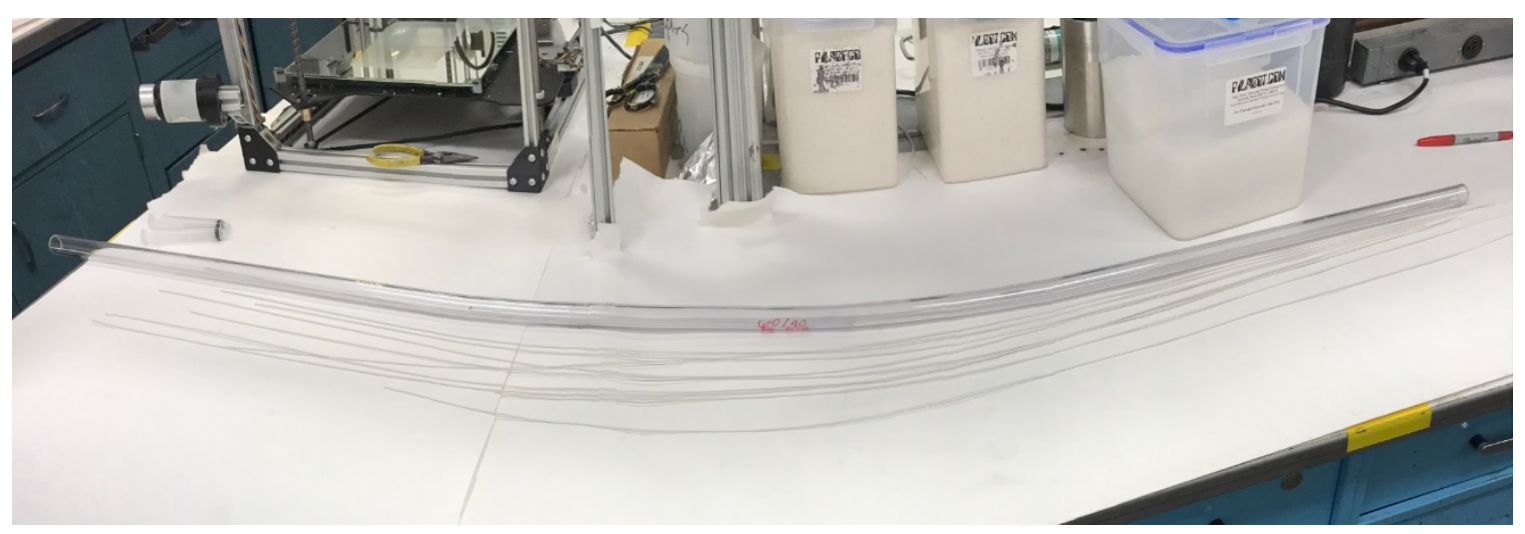

Fig. 3. Picture showing several segments of extruded filaments containing a $60 \%$ volume concentration of boron nitride particles. These filaments were stiff and had to be fed by hand into the printer's nozzle. 


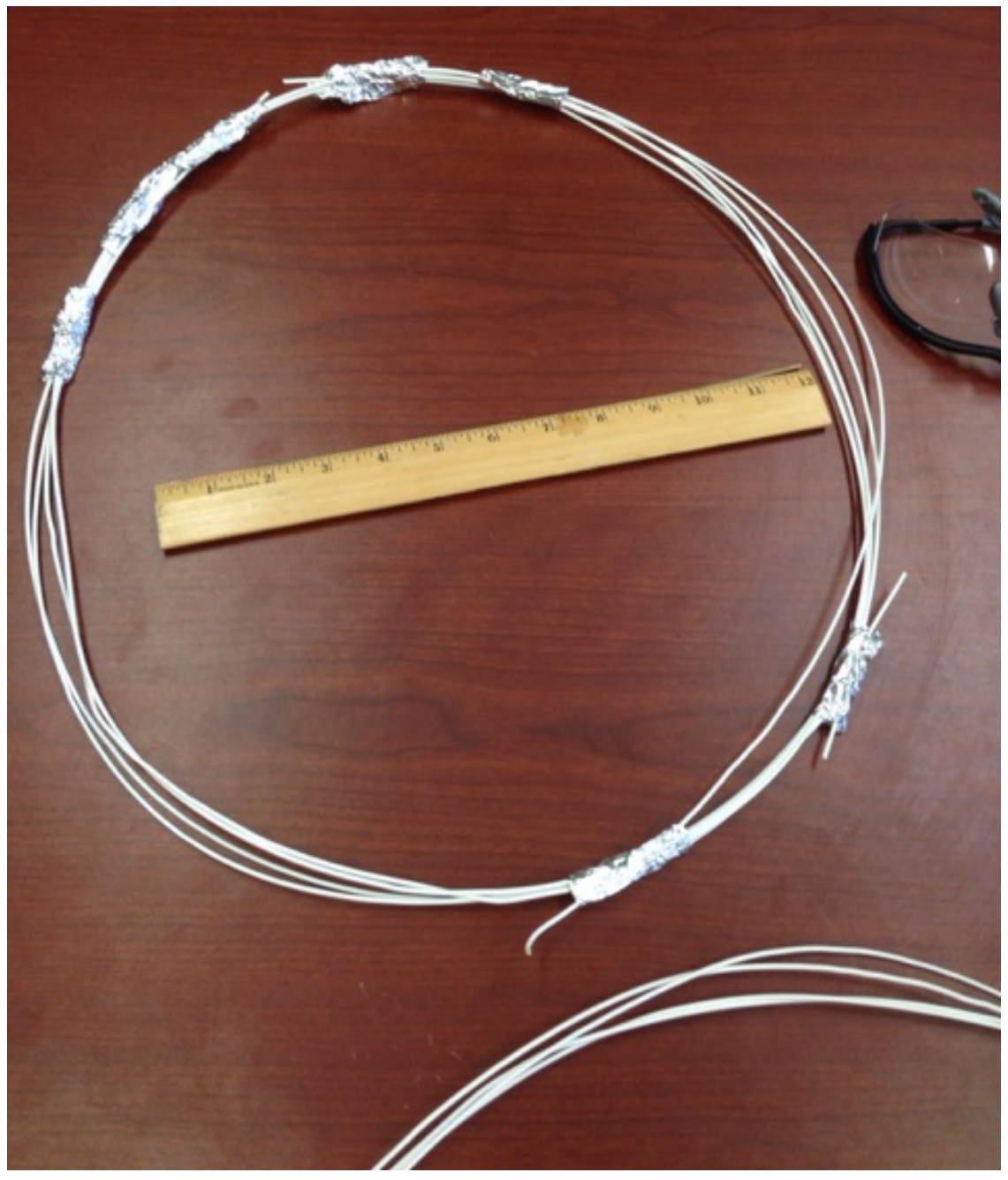

Fig. 4. Picture of extruded filaments with a $33.7 \%$ volume concentration of boron nitride particles, illustrating their flexibility. 


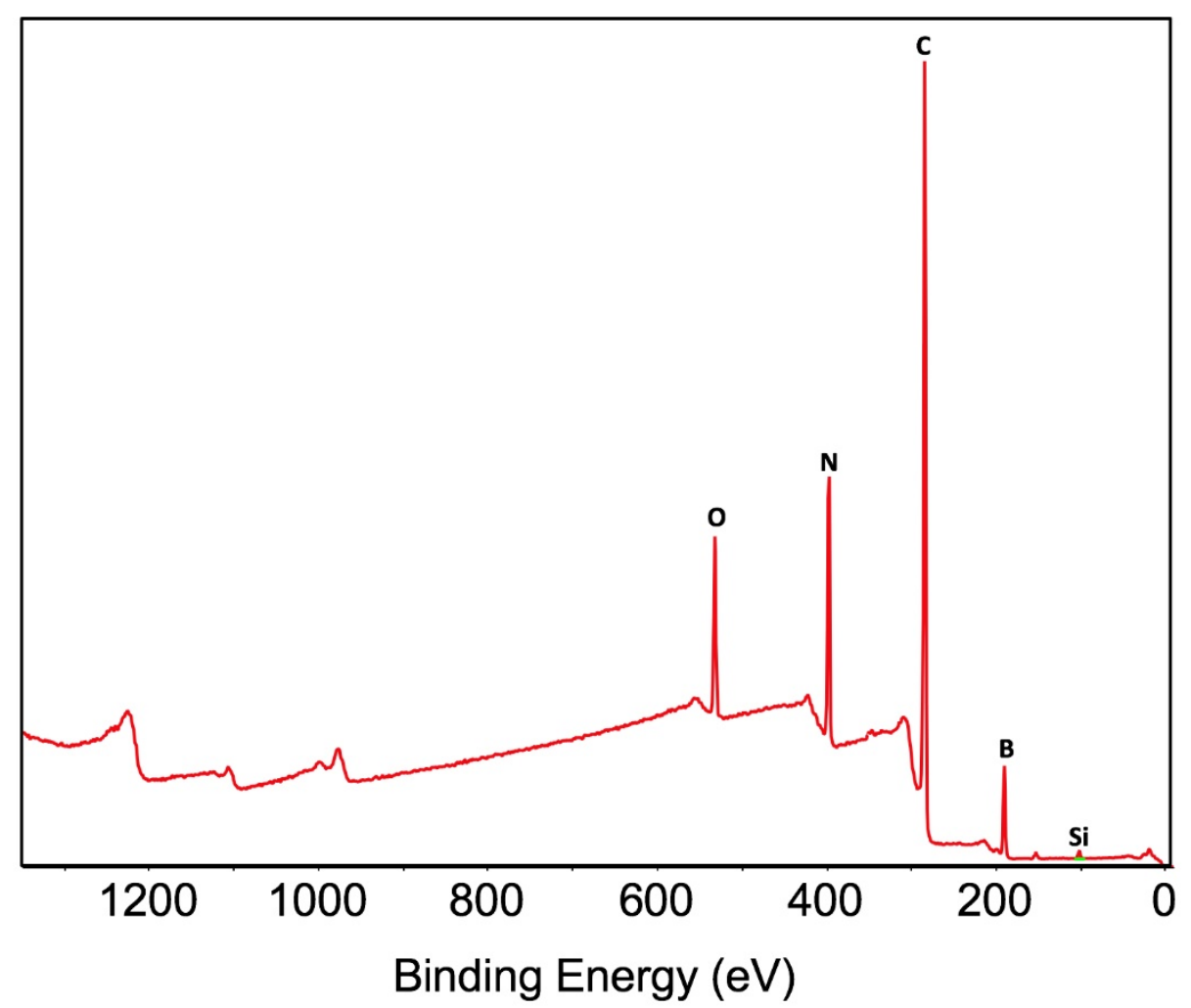

Fig. 5. Spectrum from the longitudinal cross-sectional surface of extruded filament identifying the elements present. 


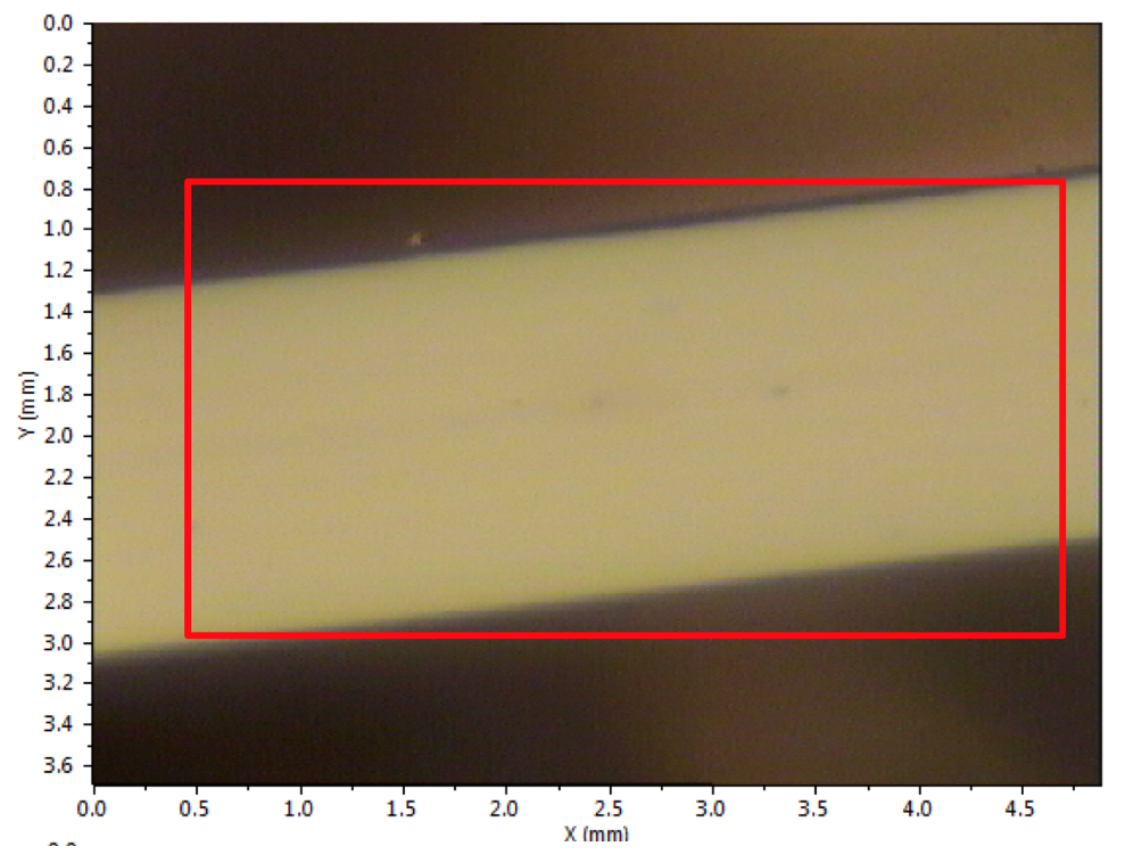

(a)

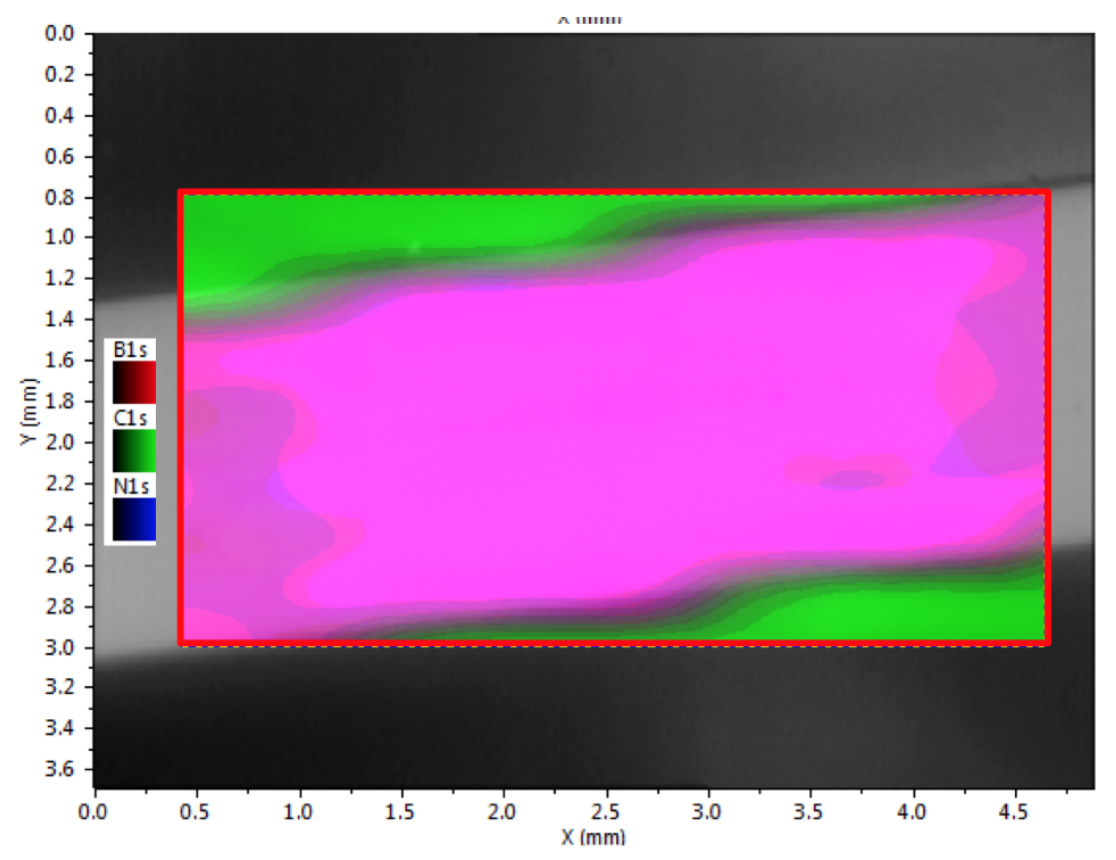

(b)

Fig. 6. Chemical distribution in extruded filament. (a) optical image of longitudinal cross section of the filament. (b) distribution of boron, carbon, and nitrogen in analysis area. The light magenta color results from the overlay of red, green and blue, indicating the presence of boron nitride and carbon from the thermoplastic binder. 


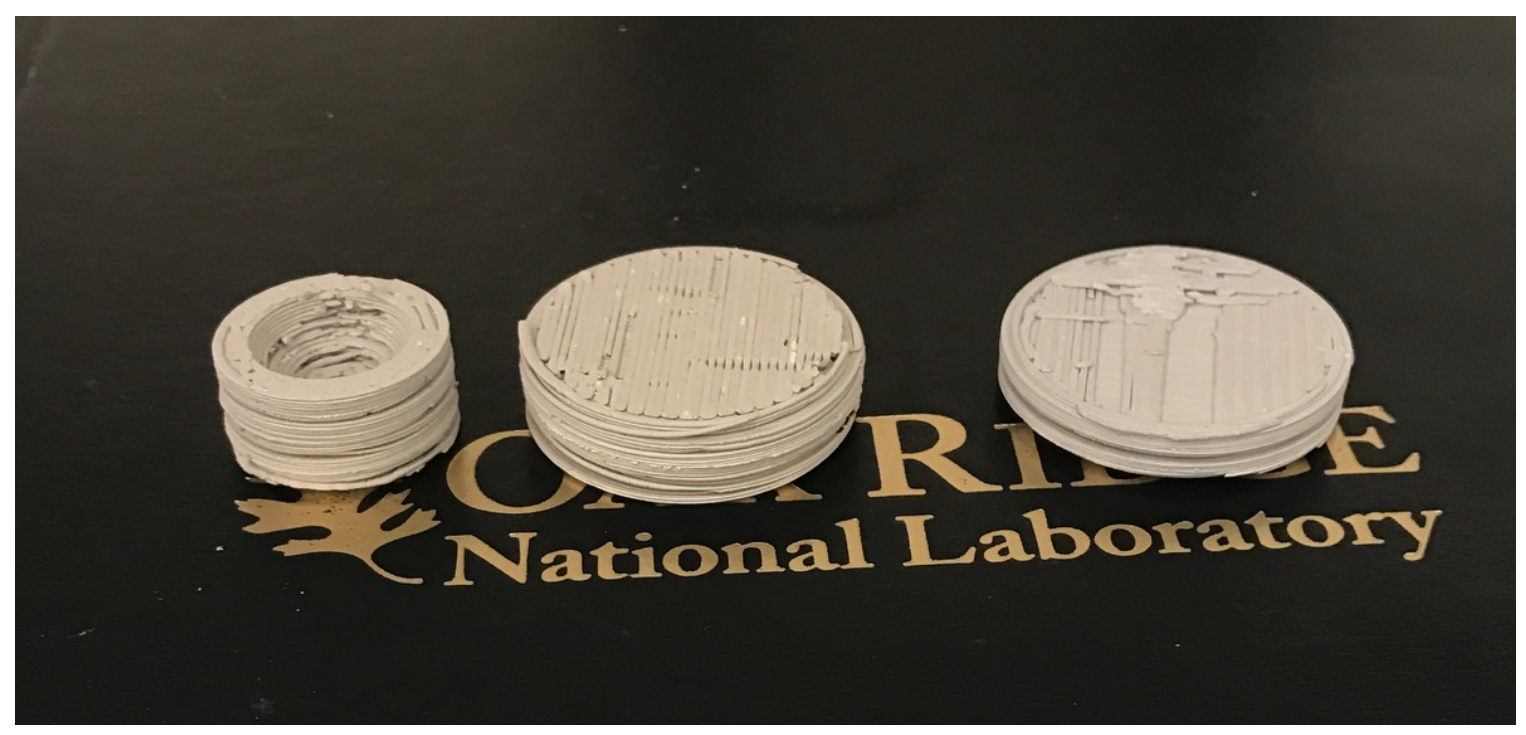

Fig. 7. Picture of two disks and one crucible 3D-printed using an extruded filament containing $50 \%$ volume concentration of boron nitride particles. The diameter of the disks is $38 \mathrm{~mm}$. 


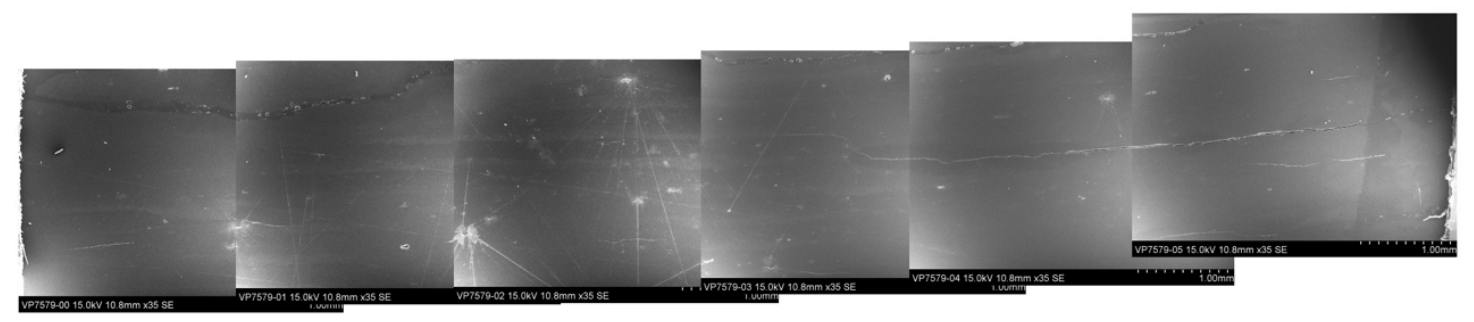

Figure 8. Scanning electron micrograph of the cross-section of sintered BN disk 


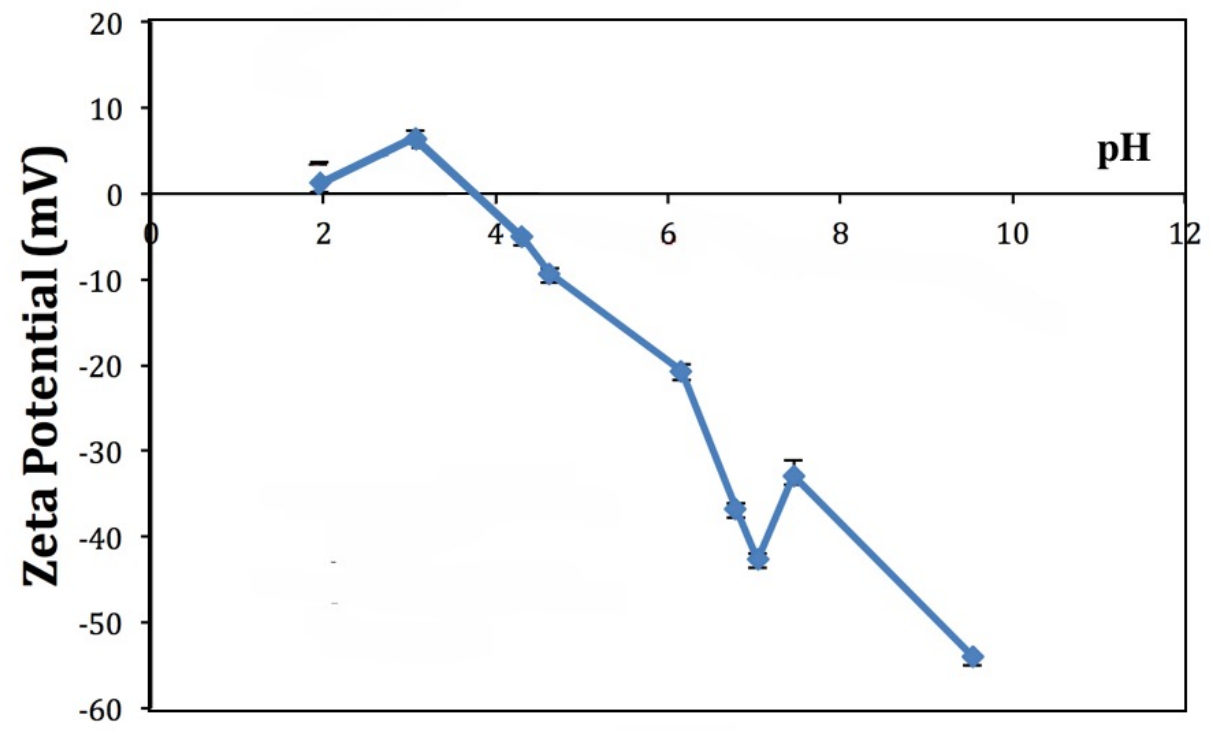

Fig. 9. Zeta potential as a function of $\mathrm{pH}$ for dilute solution of boron nitride powders. The symbols and error bars reflect the average and one standard deviation about the mean, respectively, of ten individual measurements. The solid line is merely a guide to the eye. 


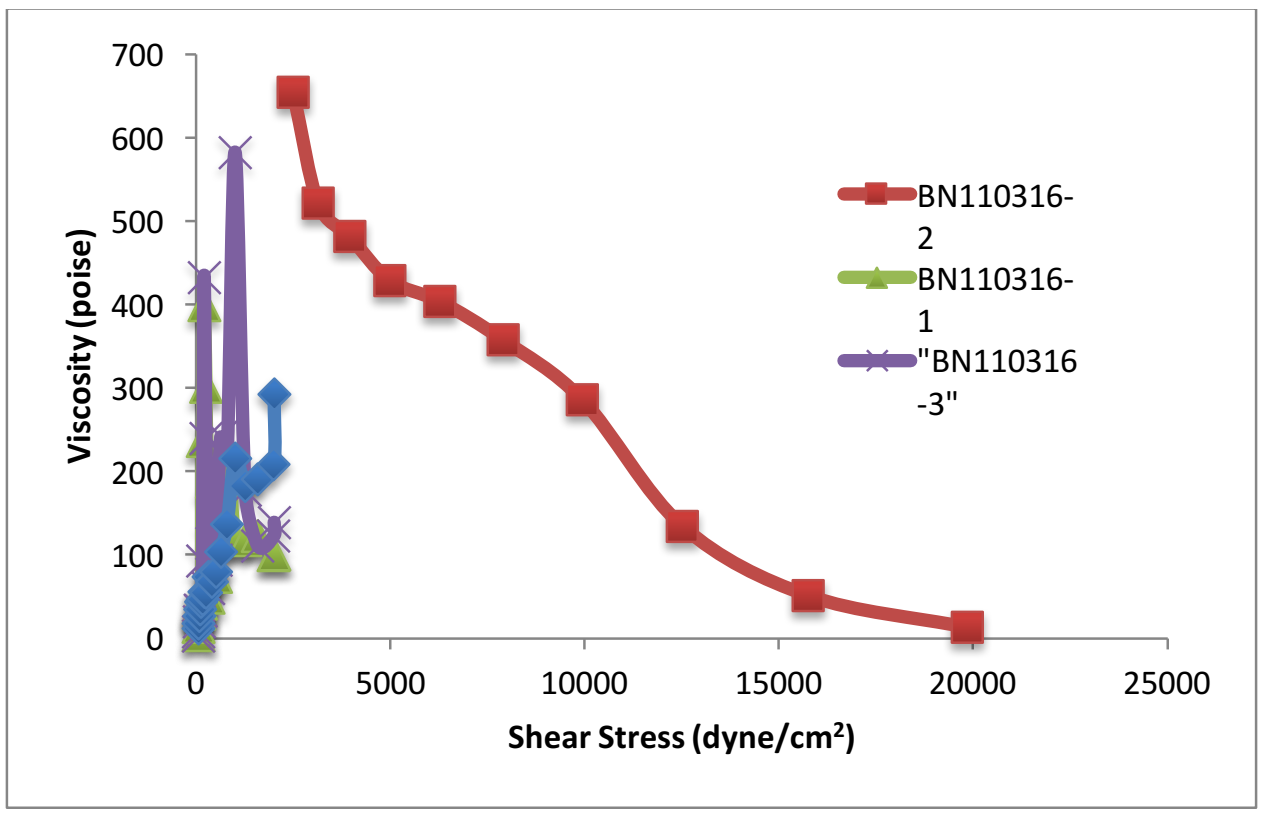

Fig. 10. Apparent viscosity as a function of shear stress for boron nitride suspensions of varying solids loading and solvent composition. The solid lines merely guide the eye. 


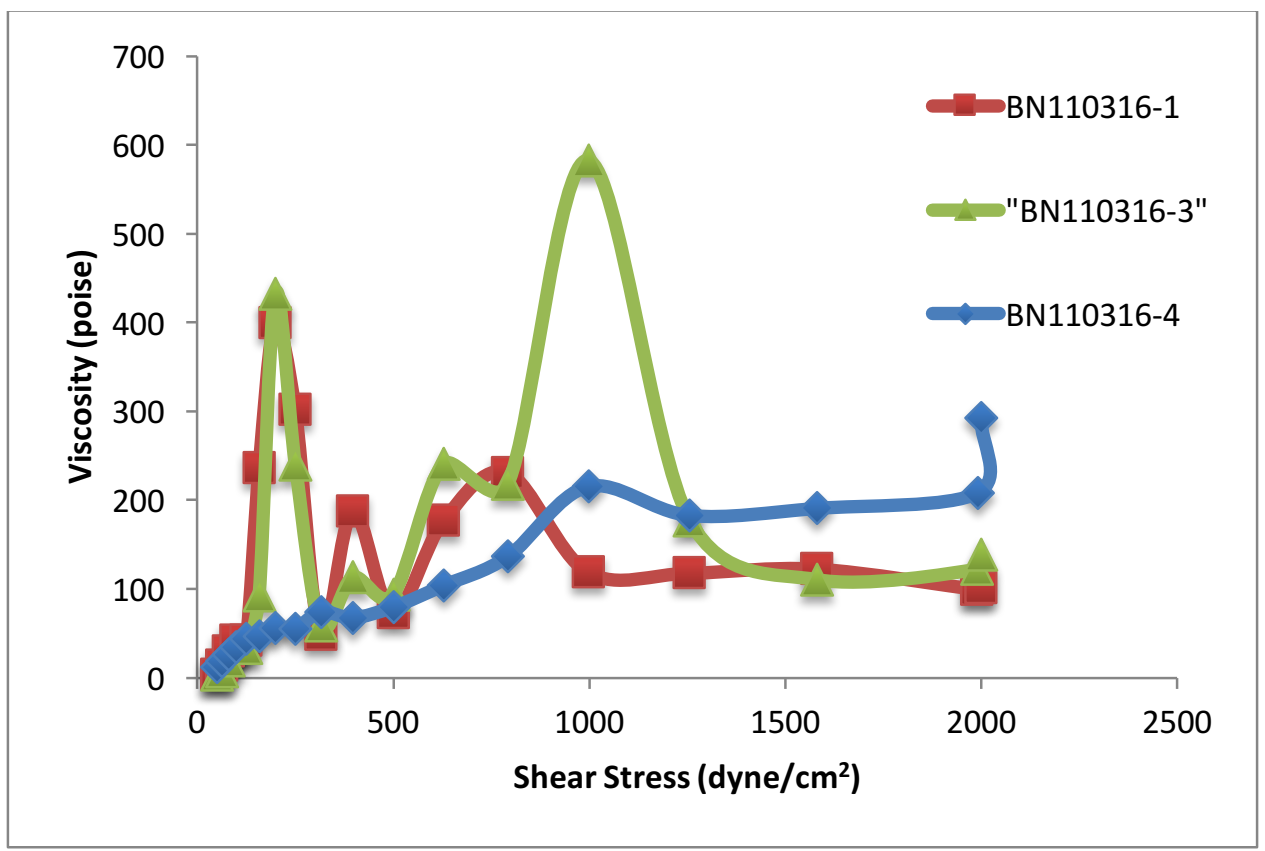

Fig. 11. Magnified view of the apparent viscosity as a function of shear stress for boron nitride suspensions of varying solids loading and solvent composition. Solid lines merely guide the eye. 


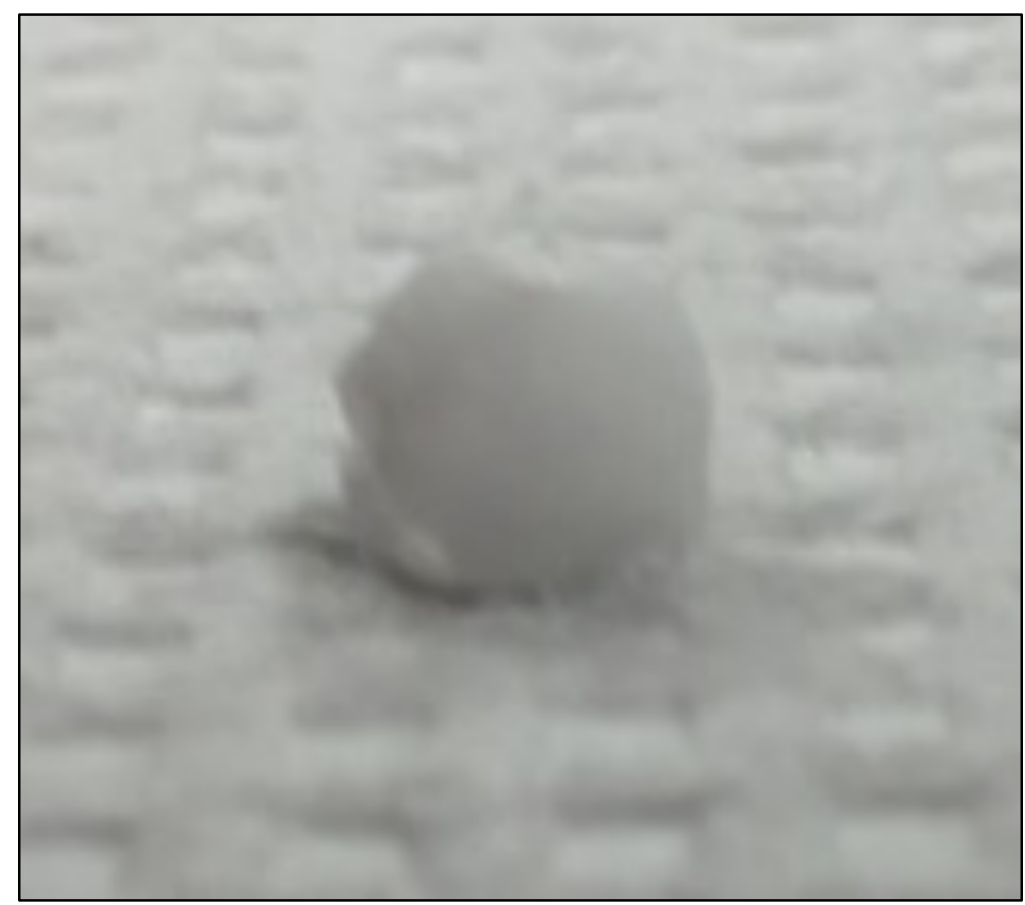

Fig. 12. Droplet containing a $26 \mathrm{vol} \%$ concentration of boron nitride with $2 \mathrm{wt} \%$ cationic dispersant polyethylene imine in deionized water suspension. 